\title{
Accessibility and Inclusion Issues in Library Acquisitions: A Guideline to Evaluating and Marketing the Accessibility of Library E-Resources
}

\section{Author}

Kerry A. Falloon, GUNY-College of Staten Island

\begin{abstract}
The purpose of this study is to emphasize accessibility and inclusion issues within academic libraries in the United States, specifically in compliance with the Americans with Disabilities Act (ADA) and other federal laws relevant to acquisition services. A review of best practices for evaluating, purchasing, and marketing electronic resources is undertaken with an understanding of U.S. federal law and regulations in relation to purchasing and marketing, specifically Section 508 of the Rehabilitation Act of 1973 and the ADA Standards for Accessible Design (2010). Few other recent studies document the exact application of evaluating products and services for users with disabilities in acquisition workflows and electronic resource implementation practices. As a model for other libraries, the author discusses using LibGuides as an outreach tool to disseminate information and documentation dedicated to disability issues among City University of New York (CUNY) librarians. The methodology of this study is to share best practices at the College of Staten Island (CSI) Library-CUNY with other academic libraries. The results will hopefully lead to more inclusive acquisition purchasing practices and more diverse marketing initiatives within academic libraries. The conclusion of the study is that purchasing and marketing workflows need to be redesigned to be universally applicable to all library users.
\end{abstract}

Keywords: acquisition services, electronic resources, workflow management, marketing, accessibility, inclusion, diversity, LibGuides, disability law

$\mathrm{T}$ The discussion and analysis of inclusion and accessibility issues within library acquisitions are essential due to disability laws and regulations, as well as pertinent decisions related to higher education in the United States. Acquisition services as a unit is ethically and morally responsible for following these mandates when investigating, evaluating, acquiring, and maintaining electronic resources. This evaluative role may also be delegated to an electronic resources librarian, an access and inclusion librarian, or a library committee dedicated to disability issues within a library. Commonly, more than one person is involved in the workflow process for determining if a resource or a service is accessible to individuals with disabilities. Typical library eresource workflows need to be redesigned to include the additional step of evaluating the accessibility, not just the usability, of the product or service. During the implementation process after acquiring an electronic resource, marketing is necessary to promote the 
resources acquired so increased usage can justify cost. As a result, marketing and outreach committees have become standard in many library settings. When assessing the inclusiveness of library marketing and outreach techniques, additional processes are needed to be inclusive of individuals with disabilities. The purpose of this study is to educate acquisition librarians attempting to integrate best practices in evaluating the accessibility of acquired products and services into current workflows.

\section{Background}

\section{Legal Issues}

As discussed, acquisition and electronic resource librarians need to be more aware of disability law compliance when determining collection development practices and acquiring new digital collections in academic libraries. The first step, for the beginner librarian, is to understand relevant U.S. federal law governing accessibility guidelines for programs and services, specifically in higher education. Section 504 of the Rehabilitation Act of 1973 requires that programs or activities receiving federal funding be fully accessible. It also states that individuals with disabilities have the right to receive reasonable accommodations to make these services accessible. The Americans with Disabilities Act (ADA) of 1998, amended in 2008, mandates that places of employment, commercial facilities, all government agencies, and public accommodations be equally accessible to individuals with disabilities (Guyer \& Uzeta, 2009). ADA upholds design standards, in particular the ADA Standards for Accessible Design (2010), which is useful in developing compliant marketing practices, especially section 703, which discusses the needed elements in signage.

There are no specific roadmaps on making e-resources accessible from either Section 504 or ADA, but librarians will find directives in recent interpretations of the laws by the U.S. Department of Education, Office of Civil Rights, and the U.S. Department of Justice (DOJ), Civil Rights Division. In particular, the 2010 "Dear Colleague Letter: Electronic Book Readers" (DOJ \& Department of Education, 2010) to college and university presidents mandates that all emerging electronic and information resource technologies be accessible to individuals with disabilities. This response came out of the June 2009 settlement between the National Federation for the Blind against Arizona State University (ASU) and the Arizona Board of Regents. At that time, ASU began a pilot program to distribute electronic textbooks to students via the Kindle DX. However, the Kindle DX supported only limited text-to-speech capabilities for the print-disabled population (Association of Research Libraries [ARL], 2012). In essence, this library service was a violation of both the Americans with Disabilities Act and the Rehabilitation Act of 1973 since the e-textbook pilot project was not fully accessible to all students. This emphasizes the point that even for "pilot" programs, technology needs to be universally accessible. As an example, the CSI Library recently implemented a pilot project in demand-driven acquisitions (DDA). In determining what e-book platform vendor to select, EBSCOhost e-books were chosen due to not only the usability and familiarity of the platform by library patrons, but also because e-books downloaded in PDF format have optical character recognition (OCR), which makes them immediately recognizable by a screen reader. Another leading competitor has image, not text-based, downloadable 
PDFs, which will not interact with screen readers. The ebrary platform does have a screen reader accessibility mode for displaying the book's content in a readable text mode, or a request is sent to technical support by a librarian so a user's account can have the text mode enabled. Yes, this platform is adaptable, but it is not completely "barrierfree"; hence, another vendor was chosen.

Section 508 of the Rehabilitation Act of 1973 (amended in 1998) states that all electronic and information technology developed, procured, maintained, or used by the federal government or federally funded programs has to be accessible to individuals with disabilities (Section508.gov, n.d.). Out of this revised amendment, the federal government developed tools to evaluate electronic resources acquired through Voluntary Product Accessibility Templates (VPATs) and Government Product Accessibility Templates. Government Product Accessibility Templates evaluate how government-developed products or services conform to Section 508 standards, whereas VPATs evaluate commercially available products or services (Section508.gov, n.d.). Next, the Assistive Technology Act of 1998 (amended in 2004) seeks to provide adaptive technology (AT) to people with disabilities through federally funded grants so individuals can participate equally in education, employment, and community activities (Assistive Technology Act, 2004). In higher education, the adaptive equipment provided through these federal funds does not have to be the best technology available, but does need to provide the needed accommodation. In general, academic libraries are vested in providing AT to their patrons; however, this does not preclude the evaluation of web content that needs to interact with AT.

The Twenty-First Century Communications and Video Accessibility Act (GVAA) was signed into law in 2010 to update federal communications law. It modernizes communications services to include 21 st century technologies such as Voice over Internet Protocol (VoIP), non-VoIP services, instant messaging, and video communications (Federal Communications Commission, 2015). The CVAA includes text messaging and e-mailing in its revisions. Applicable library-vendor-related communications include OCLC's QuestionPoint chat reference, Adobe Captivate, Camtasia or Guide-on-the-Side tutorials, and course management systems, like Blackboard, that have to be compliant in a library setting. The CVAA's goal is to also require products and services using broadband technologies, e.g., smartphones and iPads, to be fully accessible to people with disabilities. It is the responsibility of an academic library to ensure commercially available products conform to these standards since the burden of complying with disability law rests with the facility providing the service or product, not the vendor, in a free marketplace.

As a final resource, librarians can refer to the guidelines of the World Wide Web Consortium (W3C), an international community dedicated to developing accessibility standards on the web. The Web Content Accessibility Guidelines 2.0 (WCAG), developed by $\mathrm{W} 3 \mathrm{C}$, provide web content creators, such as web librarians or reference librarians, with standards for developing accessible web content (W3C, 2008). HTML content is readily accessible to screen readers and is adaptable, as opposed to non-HTML content, which has its own distinct accessibility issues. Non-HTML content includes PDFs, Word documents, Excel spreadsheets, and PowerPoint presentations. WCAG 2.0 suggests techniques such as providing alternative text for non-text content (e.g., images) and 
including features such as closed captioning, audio descriptions (i.e., "the man opened the door quietly"), and transcriptions for multimedia resources. A librarian can also test the navigability of an online resource by using keyboard tabbing and by looking for characteristics such as good color contrast, large font size, and readability. These guidelines can also assist librarians at the point of creating a resource so there is no barrier to access, as opposed to re-adapting a resource after discovering an accessibility issue. In sum, WCAG 2.0 gives content creators resources for complying with Section 508 standards.

\section{Accessibility and Purchasing Practices}

Acquisition librarians need to be aware of best-practice guidelines for purchasing procedures, developed by national library and international library organizations, when evaluating for accessibility. The author suggests ASCLA's "Think Accessible Before You Buy Toolkit" (ASCLA, n.d) and the ALA's policy on "Purchasing of Accessible Electronic Resources Resolution" (ALA Council, 2009) as important documents that give guidance to librarians when implementing accessibility standards in current workflow practices. The "Accessibility Information Toolkit for Libraries," created by the University of Toronto and the Ontario Council of University Libraries (2014), is also noteworthy because it focuses on inclusive procurement practices. Lastly, IFLA's document, "Key Issues for E-Resource Collection Development: A Guide for Libraries," concentrates on accessibility requirements that should be addressed in licensing agreements and discusses universal design standards (Johnson et al., 2012). The ARL Accessibility Working Group's (2014) "Web Accessibility Toolkit: Making Digital Resources Usable \& Accessible in Research Libraries" is another beneficial resource. In essence, if a librarian knows how to create accessible content, then evaluating vendor-created content based on the same principles is more effortless and understandable.

Many library acquisition units are beginning their understanding of evaluating and acquiring e-resources with accessibility issues in mind. The CSI Library and CUNY's Office of Library Services are both attempting to tackle this issue in a concerted and wellplanned approach because electronic resources have not been consistently evaluated for accessibility. As the CSI Library made it a priority with new policies and procedures, a movement started in CUNY's Office of Library Services with GUNY's electronic resources librarian encouraging GUNY librarians to question vendors on accessibility issues prior to proceeding with licensing agreements. The CSI Library's materials budget of approximately $\$ 800,000$, of which $\$ 600,000$ is dedicated to e-resources, makes it an essential undertaking at the campus level, in addition to GUNY resources. California State University (CSU), with its Accessible Technology Initiative (ATI), is a leading public university system that has established procurement procedures and VPAT training for its various departments (CSU, 2016). It can be used as a model for other public university systems in the United States.

Acquisition units often handle the purchasing of other library materials, such as computer equipment, furniture, and software. This might include adaptive equipment, such as large print keyboards, furniture with raiseable tables, and CCTV screens that magnify text. At CSI-CUNY, the library works with the campus's Center for Student Accessibility to evaluate the library's environment, provide adaptive technologies, and purchase new library software for students registered with the office. The University of Washington's 
"Disabilities, Opportunities, Internet-working, and Technology" DO-IT program (DOIT, 2016) provides some useful suggestions regarding adding accessible technology or equipment to a library environment. Outside of the library, there are also AT resources available through local chapters of the National Library Service, which provides the very popular e-book service BARD, or Braille and Audio Reading Download (National Library Service for the Blind and Physically Handicapped, 2015). Likewise, state commissions for the blind and visually impaired (CBVI) assist students from birth to the age of 21 by providing in-home software and technology. A librarian can sign up a patron with a disability to BARD or recommend a student to these GBVI services.

If academic libraries need to evaluate whether patron computers should be loaded with a screen reader or a magnifier or if they should purchase other software, the author gives the following recommendations on where a library can start. ZoomText is a screen reader program that enlarges, enhances, and reads aloud what is on a computer screen, such as text and images (ZoomText, 2016). It is a program that requires training but is an invaluable tool for print-disabled individuals. It can be costly but is a worthwhile investment to libraries. Downloading free magnifiers onto desktops is another solution, and, starting with Windows 7, downloadable magnifiers are included for free. The Microsoft Office 2010 suites, and later versions, have built-in accessibility features and helpful tips to create compliant content. Kurzweil 3000 is another suggested software program for learning-disabled students. It features text-to-speech in multiple languages; reads text and web pages aloud; and includes vocabulary study guides, word prediction, and a talking spell-checker as a few of its tools (Kurzweil Education, 2016). It can benefit every type of student, such as the auditory learner, the bilingual student, and remedial students without a learning disability. Likewise, the software program Dragon NaturallySpeaking is a speech recognition program that turns talk into text and allows users to control a computer and its various programs through speech. It can be very helpful for physically challenged and learning-disabled individuals, since it can also be accessed remotely with an account name (Nuance, 2016). Another great resource is Green \& Blair's (2011) guide on assistive technologies in libraries, which can support libraries enhancing their current AT by acquiring new technologies.

\section{Universal Design in Products}

When accessing a library's physical space, products, or services, the concept of universal design is essential. UD has existed for some time in the area of library architecture and spatial design. As defined by Guder (2014), it is a term that can mean "different things depending on the context and audience, and the direction or goal of the design process" (p. 229). In general, UD means that a library designs its facility and services for individuals with a broad range of abilities and disabilities. In terms of physical space, it refers to barrier-free access to and within a library building. In terms of public access services, we can evaluate whether a library's various service points are "barrier-free," including library instruction sessions. Zhong (2012) introduced Universal Design for Learning (UDL) as an "emerging paradigm to design course instruction, materials, and content to benefit people of all learning styles without adaption or retrofitting" (p. 33). For the purpose of this study, the CSI Library reviewed the practical applications of incorporating the design principles of UD into, as Guder mentioned, "principles that make better products or services for all, whether these services or spaces are provided 
physically or digitally" (p. 229). It is well known that a library is not only a physical space, but also a virtual space or portal through which patrons access a variety of digital resources. Whether using WCAG 2.0 or VPAT statements to evaluate digital resources for Section 508 compliance, ensuring products are accessible benefits a wider group of students, including individuals with English as a second language (ESL), the elderly or the aging population, people from different cultures, and individuals with different learning styles. The two recommended software programs, Kurzweil 3000 and Dragon NaturallySpeaking, inherently embody the concept of UD in that both benefit many different populations of library patrons with their features. For instance, an ESL student or auditory learner can benefit from Kurzweil 3000. Also, an aging individual with poor vision or an individual with poor fine motor skills can benefit from the voice commands of Dragon NaturallySpeaking. Moving forward, acquisition librarians are striving for a new workflow paradigm when acquiring new e-resource products. Four top questions a purchasing agent can ask is if a product or service is accessible (i.e., interacts with adaptive technology), adaptable (i.e., provides alternative options such as text only), supportive (i.e., provides accommodation without a hindrance), and will the product benefit all types of users (i.e., is the concept of UD inherently built in?) (Guder, 2014).

\section{Evaluating Electronic Resources}

\section{Implementing New Workflows}

The movement to transition from print to electronic resources began in libraries over a decade ago, particularly with electronic serials, and the complexity of library e-resource workflows has been constantly evolving ever since as technologies continue to change. Anderson (2007) noted that traditional workflows need to be broken down and redesigned into new workflows, with patron services as its goal. In essence, Anderson's declaration fits nicely into the accessibility and UD conundrum libraries are facing in keeping patrons with disabilities at the forefront in all electronic resource workflow and decision-making processes. If we keep the UD paradigm alive when re-creating electronic resources workflows, what would this redesign look like? At the CSI Library-CUNY, the library was not looking at completing a workflow analysis, since workflows could not formally be established because of an electronic resource librarian vacancy lasting several years. As a result, the Techniques for Electronic Resource Management (TERMS) by Emery and Stone (2013) was used as the model for conceptualizing all and any future workflows in all aspects of electronic resources management, including evaluating for the accessibility of products and services. The simplicity of the model had the buy-in of both the acquisitions librarian and newly appointed electronic resources librarian. Plus, TERMS has been well utilized since its inception in eight other electronic resource management studies at the time of this study.

If adopted by acquisition and/or electronic resource librarians, TERMS would involve the workflow processes of investigating, acquiring, implementing, evaluating, reviewing, and canceling/renewing digital resources (Emery \& Stone, 2013). As part of this workflow paradigm, electronic resources will also be evaluated on whether an e-resource is accessible, adaptable, supportive, and can be used by patrons of all abilities. Throughout the remainder of this study, the author will utilize TERMS as a conceptualized workflow 
model for integrating accessibility issues in the evaluation, selection, and marketing of electronic resources. Step 1 is to investigate new content for purchase or addition into a library's collections. In this first step it is useful to look at a vendor's VPAT statement, discussed earlier. Libraries for Universal Accessibility has created a VPAT repository that can be helpful for purchasers (LUA, 2014). Libraries can also create their own repository using a web tool such as LibGuides (Falloon, 2015). If a vendor does not have a VPAT statement, a library can request that a vendor complete one. A library can also create a customized accessibility checklist, as did CUNY's Office of Library Services (Egan, 2016). This particular checklist was adapted from ASCLA's "Internet and Web-based Content Accessibility Checklist" (ASCLA, 2016). Another reputable example is the Tatomir Accessibility Checklist, which rates an e-resource based on accessibility criteria (Tatomir \& Tatomir, 2012). If an e-resource fails three or more of the ten accessibility elements on the checklist, the e-resource is rated as marginally accessible on the low end or inaccessible on the high end. This can assist in an initial investigation of a resource or in reviewing already acquired resources for re-evaluation to see whether they meet accessibility standards.

A library should never exclusively depend on the information a vendor provides in a VPAT statement, verbally, or in any other written documentation. As DeLancey (2015) found, the accuracy of vendor-supplied accessibility documentation can be flawed. Therefore, it is the responsibility of a library to request a free trial of a database or software to test its accessibility. In addition, a library can download the Fangs Screen Reader Emulator 1.0 or request a free trial demo of JAWS to test how screen readers will handle a database's interface (Magnuson, 2015). Lastly, a library may want to bring in a focus group made up of a target audience of individuals with disabilities to assist in the evaluation or work in conjunction with their campus disability office for a formal assessment. On the GUNY Information Technology accessibility website, it is noted that a CUNY library can "Request a product accessibility evaluation from your college's disability services office or CUNY Assistive Technology Services (CATS). For GUNYwide products, contact Computing \& Information Services (CUNY, 2016). So far, not many campus libraries have taken advantage of this freely available service, for a variety of reasons. This seems to be mainly due to a lack of awareness of the service, but it might also potentially concern some librarians to "outsource" evaluation of a library product. However, for the author, the potential benefits of this service outweigh any concerns.

A request for proposal would fit into the TERMS investigative stage, when a library solicits responses from vendors before procuring major services and products. The library can require the vendor to report the accessibility of its product or service in the request for proposal. A library needs to make sure it is a company committed to disability issues. This can be done by investigating whether a vendor has a freely available accessibility statement on their website. It can also be helpful to speak to a vendor's product developer to discuss current features and/or features that need future development. It will be up to the individual library as to whether to continue to the next step of acquiring the product if the vendor is committed to resolving any accessibility issues. Another avenue is to investigate alternative vendors who can supply a similar product or service. It would be reasonable to prefer one vendor over the other based on a substantial reason, such as including accessibility features. 
The second step in TERMS is to acquire new content (Emery \& Stone, 2013). During the procurement process with electronic resources, the licensing of digital rights management (DRM) and other contractual terms and conditions is regularly signed. Does the license address the accessibility of the product or service? Is accessibility an issue with a product's DRM restrictions? What is your university's approved accessibility language for a contract? Below is the GUNY Office of the General Council approved language:

[Vendor] shall be complaint with all federal and state laws and requirements in the provision of services under this Agreement, including but not limited to the provision for equally effective and substantially equivalent ease of use for persons with disabilities, as required by the Americans with Disabilities Act (ADA). Section 508 of the Rehabilitation Act and Web Content Accessibility Guidelines (WCAG) 2.0, level AA shall be used to evaluate minimum compliance with the ADA. [Vendor] shall indemnify, defend, and hold the University, the State of New York, the City of New York, the Dormitory Authority of the State of New York, and their respective Trustees, Employees, agents, and servants harmless for any fines, penalties, expenses, or awards related to any claims related to failure to maintain ADA compliance, including attorneys' fees, and requests for accommodations (CUNY, 2016).

The third step in TERMS is implementation. For example, a library merchant can provide navigational aids regarding setting up a product to utilize its accessibility features. When implementing the e-resource, make sure these navigation aids are available to both librarians and patrons, through either a LibGuide or other library web pages, as a communication tool. TERMS steps four and five, evaluating and reviewing, involve an ongoing evaluation of the resource, which is usually completed annually. What does this mean in terms of an accessibility review? Going back to the example of an e-book, has the e-book's platform that hosts the content changed? Are older navigational aids still applicable? Are the e-book's downloadable PDFs still text, not imaged based, so they can be read by OCR technology? Do non-text images have alternative text? Both usability and accessibility testing can be a part of the ongoing evaluation and annual review process of an electronic resource, in addition to usage statistics to determine if the product is being used.

The sixth step in TERMS is cancellation and replacement (Emery \& Stone, 2013). If a vendor is no longer Section 508 compliant or a more accessible product is found through a new evaluation process, a library should feel free to cancel their current product and replace it with a better resource. Lastly, to make sure a library focuses on accessibility in the evaluation and procurement process, it is recommended that a library include an accessibility statement in their collection development policy. At the CSI Library, the following statement was included during a revision of its collection development policy:

The College of Staten Island Library is committed to complying with relevant ADA standards, Section 504, Section 508, and Web Content Accessibility Guidelines (WCAG) in the selection, maintenance, and access to its collections. In the development and/or the procurement of online resources, the library will consider resources that are accessible and useable to all. Collection development decision-making will consider [a] product's usability with assistive technology, 
accessible alternatives, and request accessibility documentation from vendors (i.e., VPAT or Voluntary Product Accessibility Template). Inaccessible resources or issues can be brought to the attention of the Library's Collection Development Committee and/or the Library Liaison to the Center for Student Accessibility.

In addition to commercially purchased electronic resources, there is library-created content that needs to be designed with individuals with disabilities in mind. The organization Web Accessibility in Mind (WebAIM, 2016b) created a tool called Web Accessibility Evaluation, which can assist a library in determining if web content is accessible. The same tool can be used to evaluate resources on the web. In general, the ARL Joint Task Force highly recommends that accessibility and universal design be fully integrated into all procurement processes and technology planning activities (ARL, 2012).

\section{Marketing Electronic Resources}

Marketing is a significant part of the third step in TERMS, implementation, whether in promoting a newly acquired product or encouraging patrons to utilize a previously acquired resource. Since the CSI library is using TERMS as the system for conceptualizing e-resource workflows, the library will also use Emery and Stone's indepth marketing framework as part of this third step. It is also important to note that the implementation process involves the customization of database interfaces and the branding of electronic resources with organizational logos. Emery and Stone (2013) suggest that a major acquisition of a product or service will most likely need a dedicated marketing plan. They mention that "the plan should cover the needs, wants, and interests of all potential users" (Emery \& Stone, 2013, p.23). Smaller resources may not need a separate campaign and can be advertised as part of a whole library collection or service, such as an e-book. Also, a library can create an individualized marketing plan composed of determining responsibilities, actions to complete, the timing, and scheduling of marketing activities (Emery \& Stone, 2013). The CSI Library's marketing and outreach committee delegates tasks to different individuals and establishes strategic marketing schedules for the library. Emery and Stone (2013) also suggest creating a marketing plan matrix targeted to different consumer groups via different marketing channels as an initial place to start. They mentioned students, faculty and researchers, staff, partner colleges, members of the public, and users with disabilities. For the latter group, informing the Center for Student Accessibility about a recent library acquisition, along with accessibility features, would be part of a new implementation plan. Although new electronic resources should always be marketed, current subscriptions may also need to be re-promoted to increase their visibility.

In marketing, there are two types of marketing methodologies, a soft and a hard launch of a product (Emery \& Stone, 2013). For an electronic resource, a launch is activating a resource for use and getting it out to the public. A soft launch of an electronic resource is subtle, while a hard launch is impactful and larger in scale. As part of a soft launch, the activities and individuals involved include creating a catalog record with a universal resource locator link (by acquisition/e-resources/cataloger); adding it to the library's database listing (by e-resources librarian); activating EZprozy (by e-resources librarian/IT server manager); adding the resource to a discovery tool or serials management system (by e-resources librarian); and adding it to other library-generated web pages (by web librarian/reference librarian). In other words, a library is slowly introducing the resource 
to the public through a variety of access points that will naturally promote the product. Some services only lend themselves to a soft launch. For example, the CSI Library's DDA program, discussed earlier, would lend itself only to soft launch practices, such as emailing relevant faculty or librarians that the tool exists. A hard launch with intensive marketing and details for patrons would have the opposite effect of what this service intends, for patrons to discover it naturally and purchase a book based on need. A hard launch could also have a devastating effect on a DDA project, with funds being spent too quickly, essentially shutting down the project prematurely (Emery \& Stone, 2013).

As we see, some resources only need a soft launch, but Emery and Stone (2013) recommend that a soft launch always precede a hard launch. There are various benefits to doing this. First, a soft launch gives the library time to introduce and test the product through usability testing and getting user feedback. This is where further testing by a library, in conjunction with their student disability office, can be useful. This is especially true when transitioning to a new resource that might require intricate training and technical readjustments, especially for individuals with disabilities. At the CSI Library, a new CUNY discovery tool was launched in the fall of 2014. Due to the need for testing, making readjustments, and librarian training, this e-tool was rolled out at the college in a soft launch. A soft launch can also help when the timing for a hard launch is not ideal. For example, in colleges, a mid-semester or off-semester launch, when faculty and student are not on campus, will not be effective. As Emery and Stone (2013) emphasized, timing is essential when it comes to success in marketing campaigns.

The task of marketing can be delegated to different individuals in a library. It can start in acquisitions or with an electronic resources librarian, then through the outreach actions of a reference librarian as a more singular activity, and lastly collaboratively as part of a marketing committee project. A library should also consider a process for marketing in a way that promotes the concept of UD in all formats of media releases: newsletters and newspapers, library brochures and handouts, email and social media blasts, website event listings, and digital signage. Since marketing is largely visual in nature, consider making library marketing and outreach related content, whether print or digital, fully accessible to all visually, auditory, and learning impaired users. Library marketing should be inclusive, not exclusive, of certain populations.

The CSI Library has discovered that department faculty are usually the best initial target audience since they tend to promote specific library resources to their students, either verbally or through their course management tools. As part of outreach to faculty, presenting at department meetings and contacting chairpersons directly is useful if a department liaison is not available. This is where one-to-one outreach or personal relationships are essential. Educating public access services staff, reference staff, and instruction staff is important so outreach can also occur at these service points. In sum, a library needs to be proactive and consistent in making all types of media formats and methods of promotion accessible.

Library vendors can be a helpful resource when implementing a marketing campaign since they can provide needed handouts, template letters, graphics, and promotional items such as pens, posters, or widgets for library webpages. Some vendors will also contact target audiences, such as faculty members, for further promotion. It is helpful to check vendor websites or contact a sales representative for these materials. If you need to 
modify a vendor's promotional materials to be inclusive of individuals with disabilities, ask for a Word version of a document, a scalable image, or an OCR'ed PDF. Some vendors even provide large print or Braille handouts. It is the responsibility of the library to ask for these specialized items for patrons with disabilities.

\section{Library Signage}

The use of library signage as a marketing tool has been discussed by Verostek (2005) and by Jones, McCandless, Kiblinger, Giles, and McCabe (2011). These authors noted how signage, among all marketing techniques, can lead to a dramatic increase in circulation of promoted resources. For best practice in signage design, it is recommended that libraries follow the ADA Standards for Accessible Design (2010) from the United States DOJ, Civil Rights Division. Most of these standards apply only to permanent signage but can be a helpful guideline to best practices for temporary, directional, and informational signage. Ethically, libraries are obligated to be inclusive in all their signage. In general, it is suggested there be a 70\% contrast between a sign's background and lettering (DOJ, 2010). Ample color contrast is recommended, such as dark lettering on a light background or light lettering on a dark background, with black and white providing the most contrast. Be aware of color-blind hues such as red, green, and blue, and do not use color to emphasize meaning in text. Large print font is considered a minimum of 14-point type, preferably 16 to 18 point. Using large bold characters, in upper- and lowercase, and all caps for titles or using the "Strong" heading in Word are recommended. Some other suggestions are to use only Sans Serif font (e.g., Ariel, Geneva, Tahoma, Vedana), not Serif font (e.g., Times New Roman, Cambria, Garamond) (DOJ, 2010). Also, try to aim for simplicity and consistency in verbiage so as not to confuse a reader, who might be learning disabled. Some other best practices are using clear, high-contrast, non-glare matte-finish images and displaying signage in well-lit, not overly bright or dark areas. Another suggestion is to use universally understood icons or still images to effectively communicate a message, in addition to text. In general, a library needs to ensure that there is ample high-contrast, large print signage throughout the library (DOJ, 2010).

Libraries frequently use digital signage, which has flexible content and can take the form of still images, still text, animation, and/or video. Digital signage is defined as the display of information in electronic form, usually on a video display (i.e., LCD) or through a projector aimed at a screen or wall (Barclay, Bustos, \& Smith, 2010). Digital signage may incorporate sound, screen crawls, or picture-in-a-picture technology as well as interactive features such as touch-screen functionality and cell phone interaction. They are easy to update and adaptable in design (Barclay et al., 2010). Best practices for accessible digital signage are using clear, high-definition (HD) screens with a text-to-speech option, closed captioning as a basic feature, and limited text animation, which can be distracting. A library should also allow other college departments to contribute content on library digital displays as a service to the academic community, as a collaborative venture. Digital signage also enhances the variety of the messages, which increases the likelihood that patrons will pay attention (Barclay et al., 2010). A library can likewise also request advertising on campus digital signage to reach patrons not located in the library. At the CSI Library, a combination of print and digital is used to maximize the benefits of both. 
The following questions can help guide libraries to make marketing content fully accessible to visually impaired users. Is there an audio component available? Is an image easily scalable? If not, an SVG file format is recommended, which is a file format developed and maintained by W3C and is easily scalable (WAI, 2014). Can the digital version be read by a screen reader? To test whether a PDF has OCR technology, can an individual word be highlighted, not just the entire page, making it an editable document? For online marketing content, the WebAIM tool called the Color Contrast Checker can assist with determining appropriate levels of contrast for web pages that are used for marketing purposes (WebAIM, 2016a).

\section{LibGuides as an Adaptable Outreach Tool}

Library marketing committees have become increasingly popular across many university settings to market electronic resources. In 2014, CUNY's Dean of Libraries convened an electronic resources marketing committee to assist in promoting new CUNY electronic resources among all university libraries. The goal of the committee was to assist CUNY librarians in developing, sharing, and promoting marketing literature. To convey these marketing tips and tools to other CUNY librarians geographically isolated from each other, the commercial product LibGuides was used as a communication and sharing tool (Springshare, 2016). To assist in this endeavor, the author created a LibGuide devoted to accessibility practices for purchasing and marketing electronic resources, with suggestions on visual design. One component was to create a VPAT repository with accessibility statements from library vendors CUNY has contracts with.

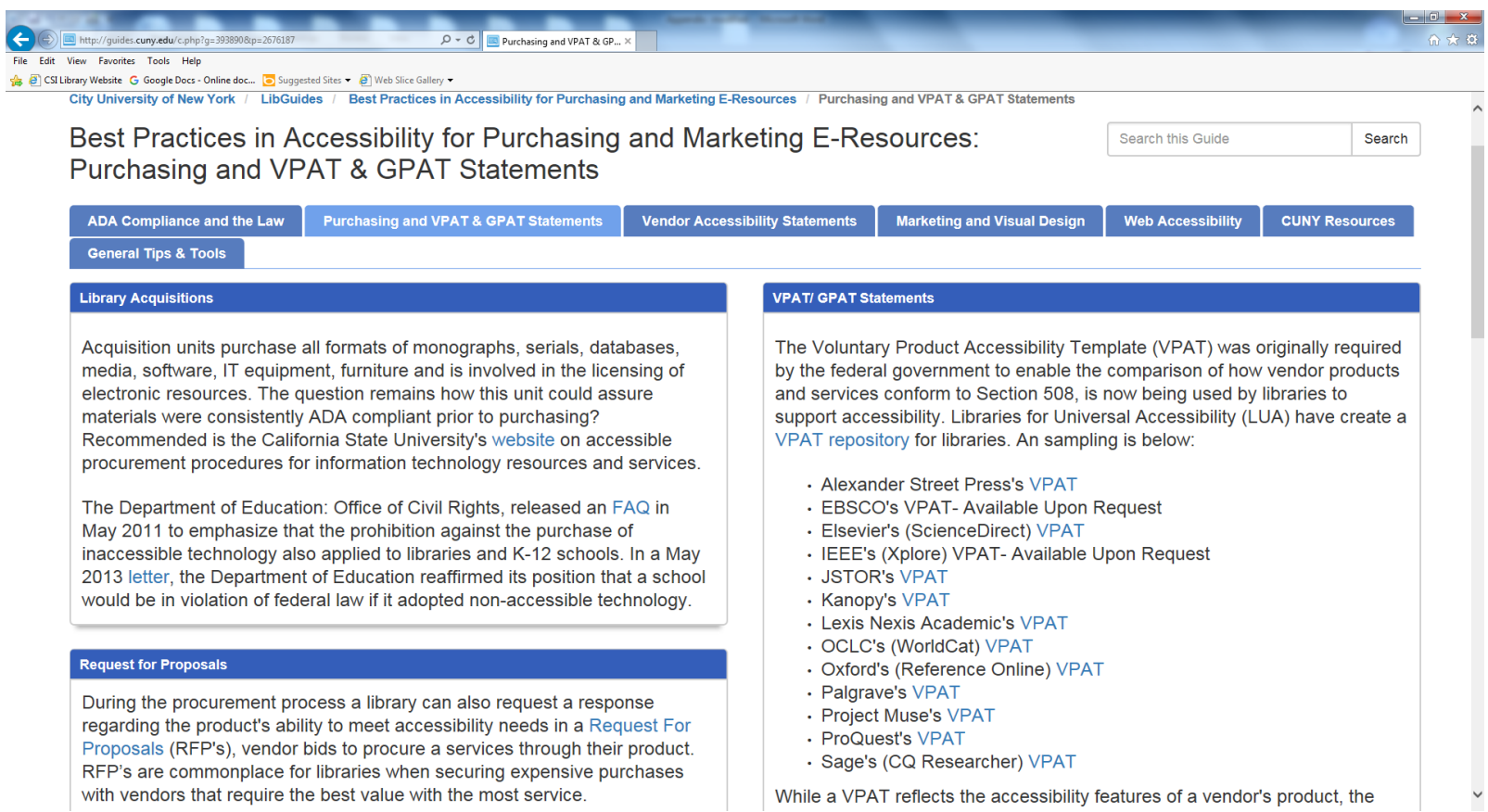

Figure 1. Screen capture of the LibGuide dedicated to inclusive purchasing practices for library electronic resources. 
The last component was dedicated to accessibility issues related to marketing electronic resources to primarily print disabled populations. The LibGuide has been popular, with many views and positive feedback from other GUNY librarians.

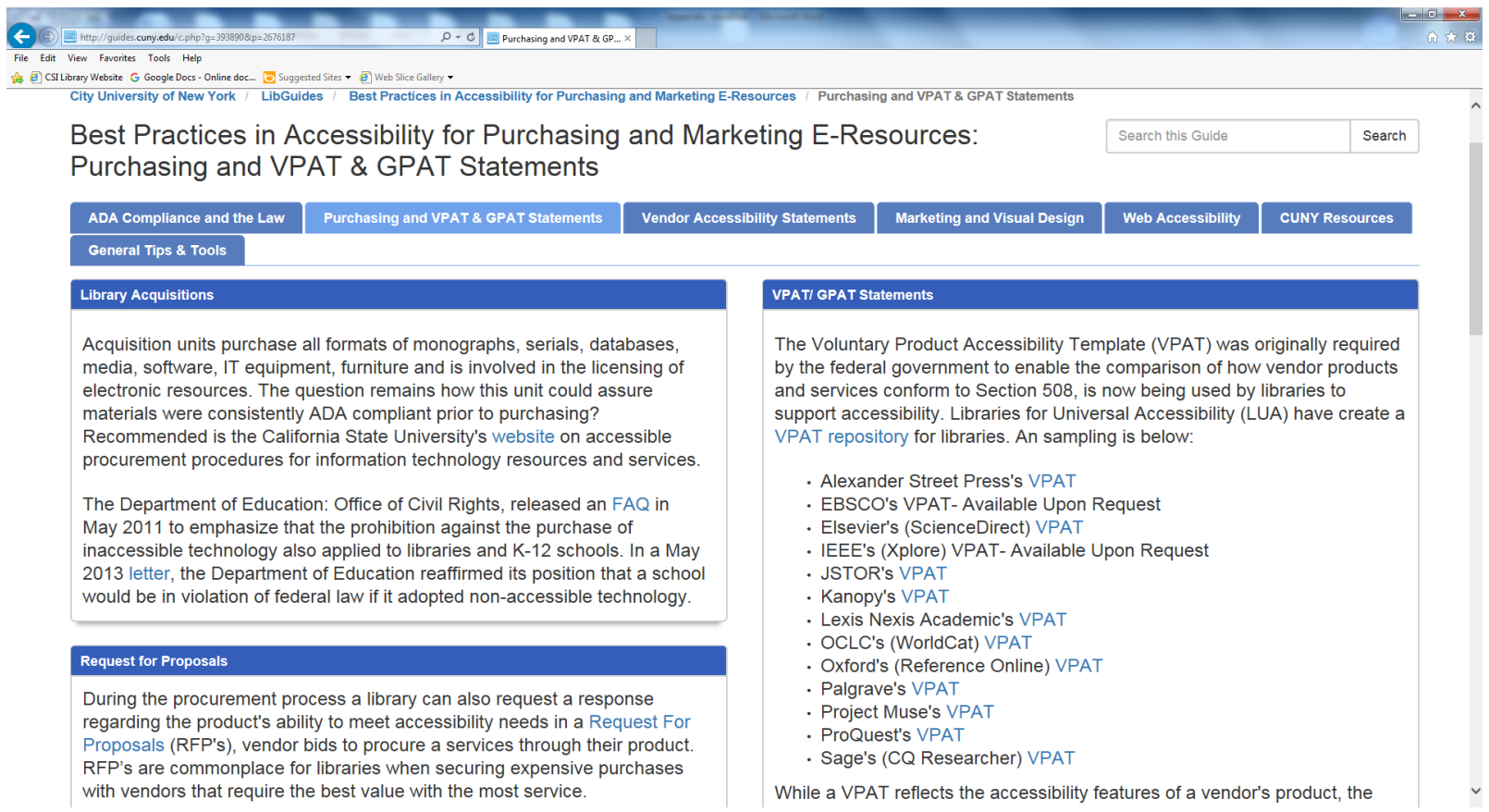

Figure 2. Screen capture of the LibGuide dedicated to inclusive marketing strategies in libraries.

As part of a CUNY marketing committee workshop on making LibGuides fully accessible as an e-resource, they suggested adapting to the limitations of this resource by limiting the number of columns on a page and instead making lists of content within LibGuide boxes. This is because a screen reader tends to navigate a LibGuide by first reading columns from left to the right and then top to bottom (Mulliken, 2015). Also, they suggested avoiding drop-down menus and including closed captioning videos. It was recommended that the gallery feature be avoided since screen readers cannot tab through this feature (Mulliken, 2015). It is important to note that there is a LibGuides subcommittee of the Universal Accessibility Interest Group (UAIG), part of the Association of College \& Research Libraries (ACRL). The goal of the subcommittee is to review LibGuides's accessibility and create a comprehensive guide for best practices with this resource, even with current accessibility updates to the latest version.

A recent ACRL TechConnect blog post discussed how LibGuide 2.0 creators can ensure that their guides are accessible and compliant using HTML source code (Magnuson, 2015). For instance, in the HTML source code editing feature of LibGuides, content creators can add alternative text to images, text to describe hyperlinks, and titled "iFrames" to embedded HTML documents like media and widgets. W3C's Web Accessibility Initiative on providing Accessible Rich Internet Applications (WAI-ARIA) defines ways to make web content more accessible to people with disabilities $(\mathrm{W} 3 \mathrm{C}$, 2014). They suggest simplifying the language of descriptive text in HTML source coding (Magnuson, 2015). In addition to the W3C's WebAIM and Color Contrast tools discussed 
earlier, there is also the W3C Markup Validation Services, which checks the validity of the HTML in webpages by rating the "mark-up" of the document as pass or fail based on errors. In addition, W3C also has LinkChecker, which can look for issues in links, anchors, and other objects in webpages (Magnuson, 2015). All of these tools can be helpful when evaluating the accessibility of an electronic resource, like LibGuides, using WCAG 2.0 guidelines.

\section{Conclusion}

As our academic populations diversify, university librarians need to become more aware of accessibility issues that can surround the acquisition and implementation of electronic resources. Inclusion issues in library acquisition services in relation to purchasing and marketing e-resources to patrons with disabilities need to be a common area of discussion and concern. About 75\% of the resources acquired by the CSI Library-CUNY are electronic in nature, but being digital does not automatically mean accessible. Acquisition and electronic resource librarians need to acquire knowledge of disability law compliance as it relates to product evaluations, purchasing decisions, marketing, and reviews. One way to achieve this is through online guides, such as the commercial resource LibGuides or the open-source product SubjectsPlus (SubjectsPlus, n.d.). These online guides are dedicated to evaluating, purchasing, and then marketing electronic resources with accessibility in mind. The final purpose of this study was to provide a workflow model on how to ensure that a digital resource is evaluated and marketed for accessibility compliance. The conclusion of this study is that practical workflow suggestions and methodologies can assist libraries with adapting these inclusive practices in acquisition services. This article hopes to further extend the discussion of inclusion and diversity issues by increasing accessibility awareness among various purchasing agents and implementation decision makers within academic libraries.

\section{References}

Anderson, R. (2007). It's not about the workflow: Patron-centered practices for 21 st century serialists. Serials Librarian, 51(3-4), 189-199. http://dx.doi.org/10.1300/J123v51n03_13

Assistive Technology Act of 1998, as amended, Public Law 108-364. (2004). Retrieved from https://mn.gov/admin/star/assistive-technology-act/1998-as-amended/

ALA Council. (2009). Purchasing of Accessible Electronic Resources Resolution (ALA CD Policy \#52 Revised). Retrieved from http://bbi.syr.edu/events/2009/docs/Purchasing_Accessible_Electronic_Resour ces_Resolution_revised_52.doc

Association of Research Libraries, Accessibility Working Group. (2014). Web accessibility toolkit: Making digital resources usable \& accessible in research libraries. Retrieved from http://accessibility.arl.org/

Association of Research Libraries. (2012). Report of the ARL joint task force on services to patrons with print disabilities. Retrieved from http://www.arl.org/storage/documents/publications/print-disabilitiestfreport02nov12.pdf 
Association of Specialized \& Cooperative Library Agencies. (n.d.). Think accessible before you buy: Questions to ask to ensure that the electronic resources your library plans to purchase are accessible. Retrieved from http:/ / www.ala.org/ascla/asclaprotools/thinkaccessible/default

Association of Specialized \& Cooperative Library Agencies. (2016). Internet and webbased content accessibility checklist. Retrieved from http://www.ala.org/ascla/asclaprotools/thinkaccessible/internetwebguidelines

Barclay, D. A., Bustos, T., \& Smith, T. (2010). Signs of success: Digital signage in the library. College \& Research Libraries News, 71(6), 299-333.

California State University. (2016). Professional development for accessible technology in the CSU. Retrieved from http://teachingcommons.cdl.edu/access/index.html

CUNY. (2016). IT accessibility. Retrieved from http://www2.cuny.edu/accessibility/

DeLancey, L. (2015). Assessing the accuracy of vendor-supplied accessibility documentation. Library Hi Tech, 33(1), 103-113. http://dx.doi.org/10.1108/LHT-08-2014-0077

DO-IT, University of Washington. (2016). Universal access: Making library resources accessible to people with disabilities. Retrieved from http://www.washington.edu/doit/universal-access-making-library-resourcesaccessible-people-disabilities

Nuance. (2016). Dragon NaturallySpeaking. Retrieved from http://www.nuance.com/dragon/index.htm

Egan, N. (2016). Library licensing guide: Licensing and procurement at GUNY. Retrieved from http://guides.cuny.edu/licensing

Emery, J., \& Stone, G. (2013). Techniques for electronic resource management. Library Technology Reports, 49(2), 5-43.

Federal Communications Commission. (2015). Twenty-First Century Communications and Video Accessibility Act. Retrieved from https://www.fcc.gov/consumers/guides/21st-century-communications-andvideo-accessibility-act-cvaa

Falloon, K. (2015). Best practices in accessibility for purchasing and marketing eresources: Purchasing and VPAT \& GPAT statements. Retrieved from http://guides.cuny.edu/c.php?g=393890

Green, R. A., \& Blair, V. (2011). Keep it simple: A guide to assistive technologies. Santa Barbara: Libraries Unlimited.

Guder, C. (2014). Universal design and the library website. Public Services Quarterly, 10(3), 229-237. http://dx.doi.org/10.1080/15228959.2014.931784

Guyer, C. C., \& Uzeta, M. (2009). Assistive technology obligations for postsecondary education institutions. Fournal of Access Services, 6(1/2), 12-35.

Johnson, S., Evenson, O. G., Gelfand, D., Lammers, G., Sipe, L., \& Zilper, N. (2012). Key issues for e-resource collection development: A guide for libraries. IFLA Acquisition \& Collection Development Section. Retrieved from http://www.ifla.org/files/assets/acquisition-collectiondevelopment/publications/electronic-resource-guide-en.pdf

Jones, D., McCandless, M., Kiblinger, K., Giles, K., \& McCabe, J. (2011). Simple marketing techniques and space planning to increase circulation. Collection Management, 36(2), 107-118. http://dx.doi.org/10.1080/01462679.2011.553774 
Kurzweil Education. (2016). Kurzweil 3000 and firefly [computer software]. Retrieved from https://www.kurzweiledu.com/k3000-firefly/overview.html

Libraries for Universal Accessibility. (2014). LUA: VPAT Repository. Retrieved from http://uniaccessig.org/lua/vpat-repository/

Magnuson, L. (2015, September 28). Accessibility testing Libguides 2.0. [ACRL TechConnect blog post]. Retrieved from http://acrl.ala.org/techconnect/post/accessibility-testing-libguides-2-0

Mulliken, A. (2015). Libguides presentation: Accessibility. Retrieved from http:/ / guides.cuny.edu/presentation/accessibility\#keyboard

National Library Service for the Blind and Physically Handicapped. (2015). BARD [software]. Available from http://loc.gov/nls/bardnls/index.html

Section508.gov. (n.d.). Section 508 Law and Related Laws and Policies. Retrieved from http://www.section508.gov/content/learn/laws-and-policies

Springshare. (2016). LibGuides. Retrieved from http://springshare.com/libguides/

SubjectsPlus. (n.d.). SubjectsPlus [computer software]. Available from http://www.subjectsplus.com/

Tatomir, J. N., \& Tatomir, J. C. (2012). Collection accessibility: A best practices guide for libraries and librarians. In G. Booth (Ed.), Library Technology Reports (Vol. 48, No. 7, pp. 36-42). Chicago: ALA TechSource.

University of Toronto Libraries \& Ontario Council of University Libraries. (2014). Accessibility information toolkit for libraries. Retrieved from http://ocul.on.ca/node/2127

U.S. Department of Justice. (2010). ADA standards for accessible design. Retrieved from https://www.ada.gov/regs2010/2010ADAStandards/2010ADAStandards_prt.p df

U.S. Department of Justice, Civil Rights Division, \& U.S. Department of Education, Office of Civil Rights. (2010, June 29). Joint "dear colleague" letter: Electronic book readers. Retrieved from http://www2.ed.gov/about/offices/list/ocr/letters/colleague-20100629.html

Verostek, J. M. (2005). Affordable, effective, and realistic marketing. College \& Undergraduate Libraries, 12(1-2), 119-138. http://dx.doi.org/10.1300/J106v12n01_09

WebAIM. (2016a). Color contrast checker. Re-trieved from http://webaim.org/resources/contrastchecker/

WebAIM. (2016b). WAVE Web Accessibility Evaluation Tool. Retrieved from http://wave.webaim.org/

World Wide Web Consortium. (2008). Web Content Accessibility Guidelines (WCAG) 2.0. Retrieved from http://www.w3.org/TR/2008/REC-WCAG20-20081211/

World Wide Web Consortium. (2014). Web Accessibility Initiative. Retrieved from http://www.w3.org/WAI/

Zhong, Y. (2012). Universal design for learning (UDL) in library instruction. College $\mathbb{E}^{\circ}$ Undergraduate Libraries, 19, 33-45. http://dx.doi.org/10.1080/10691316.2012.652549

ZoomText. (2016). ZoomText [computer software]. Retrieved from http://www.zoomtext.com/ 